PCHA Conference Publication

Organizational Frameworks Panel
Ajmal Maiwandi, Gil J. Stein,

Kitab Khan Faizi, \& Charles C. Kolb

\title{
INTRODUCTION
}

This chapter is based on the discussion session from the expert panel concerning Organizational Frameworks of Cultural Heritage Preservation. It will include aspects of the conversation that occurred between the panel members, the panel moderator, and the audience members who participated in the discussion, as well as the view points of the volume's editors. The perspectives presented below often focus on both abstract concepts and specific examples of coordination, but several key questions arise. Namely, whether there should be a model for preservation work, who should be responsible for developing that model, what kinds of largerscale institutions (such as governments) can help implement that model across a variety of organizations and cultural heritage projects, and what the role of those institutions should be. Thus, the chapter is organized into three main topics: Areas of Inter-Organizational Cooperation, Modes of Cooperation, and Future Steps toward organizational frameworks of cultural heritage preservation.

\section{AREAS OF INTER-ORGANIZATIONAL COOPERATION}

Before we examine the role, challenges, and impact-capacity of higher-level umbrella institutions in creating organizational frameworks for cultural heritage preservation, we will identify some particular areas of focus that require cooperative approaches. This section will look at how various organizations, lowerlevel institutions, and projects function cooperatively (or fail to), and what aspects of preservation work necessitate coordination from a higher level.

Cultural heritage preservation in general includes locating materials (for example, surveying or archaeological excavation) and collecting and preserving them. Object processing (cleaning or stabilizing, housing and protecting), cataloging, inventorying or creating collection databases are also a necessity. One goal should be to provide intellectual access: exhibition of materials, creating virtual collections, digitization of objects, and analog archival library and archival collections. Disaster preparedness (natural and human - created events) should be a component of these activities. A primary element of all of this this work is to employ standards for curation, protection, and documentation developed by international and national professional organizations.

A wide variety of organizations, projects, and individuals currently comprise the cultural heritage preservation community in or related to Afghanistan. It is important to emphasize that these include not only international groups but many local Afghan organizations as well. These include local public institutions such as university departments, libraries, archival facilities, a network of national and provincial museums; governmental research institutes and private special-interest groups and institutes; foreign NGOs such as universities and private culture 
organizations; the culture sections of foreign governments, and international organizations such as UNESCO. Although all share a strong commitment to Afghan culture, these organizations differ widely in scale, available resources, and specific areas of concern or focus. They represent many different but overlapping organizational missions. With all of these interested parties it would seem as though cultural heritage is in good hands. However, what often stands between these dedicated groups and a robust, effective system for preservation and education is that the nature of the work typically requires particular kinds of cooperation specific to each field and issue. Because cultural heritage consists of so many different complex components, it is only natural that heritage preservation would require a wide range of specialized expertise. This, in and of itself, means that preservation programs can only be effective if these organizations work in cooperation with one another.

There seem to be two basic modes of cultural heritage preservation deployed throughout the world. One is proactive: preventative and related to systemic processes. The other is reactive: related to emergency support for stressed systems. Both kinds of work are imperative for the survival of cultural heritage. In Afghanistan, a conflict zone for decades, the latter has been the main mode of cultural heritage preservation in recent years, and rescue archaeology, such as the Mes Aynak Archaeological Excavations (see Temori, this volume), is one example of this kind of work. Considering both the ongoing conflict and recent agenda of rapid economic growth through extraction of natural resources, it is something that we will likely see as an increasing focus in Afghanistan in the future. An early example of this kind of cooperation was the Aswan High Dam international salvage effort, which was coordinated by UNESCO in Egypt during the early 1960's.

However, the challenge for all of us, not just in the university setting, but at the setting of local provincial governments and at the level of the national government, is to push beyond the reactive mode, to move toward what one could call a proactive orientation. We can then address questions including what are the problems that exist at the national level. From there we can look forward and anticipate where the emerging threats to heritage are going to be or, more importantly, how do we envision protecting these resources. Thinking proactively, by its very nature, requires us to think at a broader level of engagement. Thus, it is almost as if two levels of action are needed at the same time, one of which benefits from coordination (reactive), and the other of which necessitates it (proactive).

Another area of cultural heritage preservation where coordination is essential is museums. Be they national galleries of archaeological collections, small topical or regional collection displays, or cultural centres, museums are meeting points for communities, both local and international (see Latify et al., this volume). Because of this, the work of museums draws support and interest from all over the world and from a variety of organizational types. Foreign museums and universities often engage naturally in partnerships with local museums, but so do research institutes, private interest groups, foreign embassies, local organizations and institutions, and 
so forth. Even between museums themselves there are typically enough partnerships to require coordination of purpose and execution.

The Oriental Institute of the University of Chicago has worked very closely for decades in partnerships with museums across the western and central Asia. One of the main thrusts of these partnerships has been training museum professionals, including conservation personnel exchanges with museums in Iraq and Afghanistan (see D'Alessandro \& Hakimzadeh, this volume). However, the conservators from the National Museum of Afghanistan have also received training at other internationally renowned institutions such as the British Museum in London. In many cases the training and methods of conservation taught vary or, occaisonaly, directly contradict one another. It has become apparent that, on quite a broad, global scale, lack of coordination has severely lessened the impact of these training efforts. Inside of the museums, it is clear that the missing element of a true organizational framework has in some cases hampered in-country training, led to duplication of efforts, helped confuse museum personnel, and wasted resources.

The management of not only capital resources, but also cultural heritage resources is a broader area of need in terms of inter-organizational cooperation. There are legal issues that come into play, especially when talking about the repatriation of looted and illicitly exported artifacts (see Simpson, this volume). For effective and long-term management and preservation, Nancy Hatch Dupree has proposed the creation of a database of cultural heritage properties (see Dupree, this volume and 2002). President Ghani, similarly, called for the development of a detailed map of heritage sites across the country (see H.E. President Ghani, this volume), not only to document and preserve heritage, but also as a planning resource so that economic development can take into account the preservation of sites and monuments that might be threatened by these projects. These proposals are essentially one and the same, but the task is enormous and the challenges are varied. There are so many components in terms of expertise, funding, logistics and security, and timeframes.

For instance, the Ministry of Information and Culture and Institute of Archaeology have registered over five thousand sites in Afghanistan, and yet that is only a fraction of what are likely tens of thousands of sites in existence. These include both historical monuments and archaeological sites, and their coexistence already suggests a necessary multitude of expertise. Many sites are located in areas of the country that are submerged in armed conflict or are controlled by dangerous factions. Thus, remote sensing of sites, using satellite imagery and other means, should be an important part of the methodology employed. This would add yet another key area of expertise to the requirements.

Creating this total heritage database would be a proactive approach that could enable Afghanistan to identify effective preservation strategies for sites with high potential to be endangered by conflict, looting, urban encroachment, and economic development. This would supplant the approach, mentioned above, that relies on rescue tactics for sites that are already damaged or destroyed. 
Hopefully, another outcome of such a database would be the promotion of cultural heritage among the general public through facilitated research and tourism, and both of which are key for sustainable cultural heritage preservation (see Latify et al., this volume). Currently, most of the tourism that occurs in Afghanistan is generated by Afghan nationals. However, there may come a time when international tourism is a major industry in Afghanistan as well. It will require another level of investment but will bring another level of economic development.

And so it is clear that from the smaller-scale, rescue-oriented projects to mid-level, capacity building and supportive projects to the large-scale, grand plan of creating an overarching living record of the total cultural heritage of the country, a solid framework for coordination is needed. Within that framework should be models for operating, for groups both individually and cooperatively.

Of course the question then arises, who should generate the models? Should they come from the organizational/expert level, or from a broader agency? And if it comes from organizations, then which ones should they be and how do they develop it collaboratively? Do we want this model to be comprehensive, that is, all inclusive of all of the issues involved in cultural heritage preservation? Or do we want it to be selective? In our deliberations, our decisions ideally are holistic or comprehensive versus selective. The question of scope is also relevant; it may be national, provincial, local, or a mixture of these.

Afghanistan has an enormous number and variety of cultural heritage properties in need of preservation. And there are, of course, various ways of achieving that in terms of collecting data, processing it, cataloging, digitizing, and disseminating it. But these are small pieces, and a key question to bear in mind is how big is this picture? In just one country alone, how much is there to be done across so many different domains? It is an enormous challenge and we must recognize that no single group can do it alone. And so the fact that so many different institutions, within Afghanistan and from the international community, are involved in this, is, in fact, a strength, because different groups will bring different kinds of expertise. And the partnerships that exist, illustrated and discussed during this conference, are really encouraging examples of what can be done by thinking both very small at the level of individual projects and thinking very big at the level of international cooperation.

\section{CREATING A FRAMEWORK: MODES OF COOPERATION}

Since it is clear that coordination of cultural heritage preservation efforts would tremendously strengthen their effectiveness and impact, it is then necessary to decide upon the structure and logistics of such coordination. Basic questions include what level of coordination the different parties should have with one another, and if it is a large framework, whether that would be flexible, based on situationally specific models of cooperation, a heterarchical model, or strictly 
centralized and hierarchical, derivative from some higher body. Models are paradigms or ideals that are conditioned by reality. Are there relevant models in the world that already exist that can be informative? Before that, even, as above, we have to ask ourselves who should decide as to the nature of the model(s) used? In Afghanistan, where there are so many local and foreign interested parties with a wide array of backgrounds and mandates, who sets the agenda and/or determines the path toward a comprehensive framework of preservation efforts?

In any hierarchical model of coordination, one obvious choice for the coordinating body is the Afghan government itself. This is a centralized governing system, not a decentralized one. Other national governments either do not have a Ministry of Culture or, if they do, those ministries take more of a ceremonial role than an active and substantial one. The Afghan Ministry of Information and Culture (MoIC), however, has been very active despite all of the limitations of resource that it has and all of the problems that come from working in the current military-political context (see Khalili, this volume). It has worked hard to develop lists of priorities and areas where it would like its international partners or donors to invest.

However, it is no simple task to be the coordinating body for all such partners. For example, when one conceives of a project for Afghanistan, how would that work fit into existing priorities, and how exactly do cultural heritage groups manage their relationships with each other and the government? Beyond the initial implementation of the project, how does the work become sustainable for an extended period of time? Also, there are mandates and roles in coordination. There are so many activities happening here whether it is in the private sector, in small organizations, art organizations, calligraphy organizations, poetry, literature, there are so many dimensions here.

To help address these issues there had been a quarterly meeting convened by the MoIC with its colleagues working in these various areas of Afghanistan's cultural heritage. They shared the issues and problems related to cultural heritage and based on these discussions the Ministry of Information and Culture would take initial steps. Following that, a program would be organized for international colleagues and key organizations working in Afghanistan to be free to operate in the place of the Ministry of Information and Culture. Hopefully this program will be revived and conduct further coordination on the part of addressing the cultural heritage of Afghanistan.

A Culture Coordinating Committee does currently exist for Afghanistan, formed by UNESCO, the Agha Khan Trust for Culture, and the Ministry of Information and Culture. It is composed of select members but includes guests who make topical presentations. This structure allows for the gathering of information about sites in remote areas of the country, such as Jam, Herat, Ghazni, Helmand, Lashkargah, etc., where few organizations can send their personnel. That information is then shared with a wider group which benefits all ongoing culture projects. The group is open and the minutes of the meetings are available to all. Because this group integrates 
the global (UNESCO), the local government (MoIC), and various experts, it should be a productive setting for the building of a framework.

This would be getting closer to a heterarchically-based organizational framework for cultural heritage preservation, but there is clearly a dividing line between the Afghan government and its partner organizations. One example of this division can be seen in the compartmented response to broad issues of site preservation. The approximately five thousand archaeological sites and thirteen hundred historical monuments that have been registered are in jeopardy. There are two basic, necessary functions in cultural heritage work, one of which is protection and the other is preservation. It is loosely understood that the national government has the mandate to protect the sites, while the expert community has the mandate to carryout the preservation work where needed. The are examples of coordination between these two aspects of the work (see, e.g., Temori, this volume), but they are rare and their cooperative efficacy is unclear.

The Ministry of Information and Culture has undertaken numerous initiatives and taken the lead on key issues such as a national registration for historic monuments, an information database of monuments. It has also partnered with the Ministry of the Interior on the protection of cultural heritage properties, specifically in the form of the 012 police force which is responsible for the properties in particular. However, the force is only 500 strong for the protection of all of the sites and monuments in Afghanistan; ideally, the MoIC can help increase the resources available for this. But a more powerful force for protection is the people themselves. Perhaps among all the challenges that Afghanistan faces regarding the preservation of its cultural heritage, public awareness is among the greatest (see Latify et al., this volume).

Regarding the issue of protection of Afghanistan's cultural heritage more broadly, the MoIC has a draft policy in place. In 2013 this policy was submitted for endorsement by the Committee of Ministers, and currently it is available in all departments of the Ministry of Information and Culture. Hopefully, soon it will be made available to all. And if the government extends this policy further, it could be enriched by including the views of all partner organizations. Thus the current process is the development and finalization of the document. Presently, it is required for organizations working in different areas of cultural affairs to cooperate with the MoIC, and it is requested that they step forward to help further enrich the policy, and help produce a firm document that could support other policies.

Even with these examples of information sharing and collaboration among experts and between experts and the government, the decision making body is still the Afghan government. And so what about other possible models of cooperation? Furthermore, we have seen theories and glimpses of how the national Afghan government and the work of expert organizations can dovetail to produce positive results, but when we factor in the cultural counterparts within foreign governments, the mixture becomes more complicated. 
Perhaps to develop a paradigm of cooperation it is important to think in new, creative ways. Afghanistan, like all nations is unique, and should develop its heritage needs to existing cultural norms and abilities to carry out preservation and intellectual access activities. The US does not work as a model because it is without a Ministry of Culture. The National Endowment of Humanities (NEH) in Washington D.C. is a kind of de facto Ministry of Culture in many aspects for the United States, as a result. And so the NEH along with the Department of State have taken particular pride in working oversees by having American institutions apply for funding to assist their counterparts in other areas of the world, particularly in conflict zones. More appropriate potential models come from Europe, notably France or Germany, or internationally, such as ICOMOS or UNESCO.

Cultural heritage repositories create collections and those collections are often in a way overseen or assisted by professional organizations such as council of museums or libraries or archives, who also set standards, or such things as cataloging or digitization or making materials accessible. Five types of repository organizations include: a) Libraries and archives (housing books, manuscripts, still and moving images, and born digital materials; b) historical and archaeological/ anthropological museums (holding material objects and documentation of these materials); c) natural history museums (material objects and object documentation of flora and fauna used by humans); d) art museums (material objects and object documentation); and e) historical organizations (material objects and object documentation books, manuscripts, still and moving images, and born digital materials).

In 2001, after 9/11, the United States began to take a greater interest in preservation of cultural materials housed in overseas repositories. And the key impetus for this change was the destruction and looting of portions of the Baghdad Museum. That particular activity resulted in the US development of an initiative to preserve the cultural heritage of Iraq. For similar reasons, the NEH was also starting to receive request for help in Afghanistan. From 2003 until now, the NEH awarded 19 grants for cultural work in Afghanistan.

But these grants and the mandates presumed by them often function and materialize through the work of the grantees, who comprise a larger field of experts than the handful of international organizations that exist perennially in Afghanistan. Thus the model for organizational framework needs to be larger than that of a single country or government or umbrella organization. And it has to be flexible.

There are a lot of problems in this area, and for the community of cultural heritage experts to effectively address these issues, there needs to be a united effort. All organizations working in this field should be hand in hand so that together they actively operate and unitedly make efforts to address modes of preserving cultural heritage, either tangible or intangible. The Ministry of Information and Culture, 
without doubt, cannot address all these issues alone with the limited resources it has available.

One model project for cooperation across fields of expertise, institutional directives, and organizational capacities has been the public-private collaboration between the Kabul Municipality and the Agha Khan Trust for Culture in the Bagh-i Babur restoration (see Sahibzada, this volume). However, one of the most challenging issues has little to do with culture, or even diverging mandates and agendas within the realm of cultural heritage preservation, but instead is the issue of security in Afghanistan. We have witnessed the destruction of the sites in many areas such as Helmand; should the security situation be an excuse? There are sites which the government can protect but maybe archeological sites are occupied, and historical monument sites are occupied by IDPs. If the national or local government is watching them and they are looted, then to what degree are they involved in the looting?

And the security problems also impact tourism, which is one aspect of a healthy national heritage program. Ironically, data from the national registration shows a slow development of international tourism in Afghanistan. For instance, Bagh-i Babur has drawn increasing numbers of foreign visitors. In Bamiyan, around 80,000 tourists visit annually. But concerning collaboration and cooperation among organizations working in Afghanistan in this area, fortunately there is some level of coordination among various organizations working inside of the country, but the hope is to slowly slowly expand that cooperative framework to dozens of other organizations in different areas that contribute to the preservation of Afghanistan's cultural heritage.

\section{FUTURE STEPS}

While there certainly have been efforts at coordination of cultural heritage preservation activities, a single, integrated system for cooperative engagement with the cultural heritage of Afghanistan does not yet exist. We have seen where certain partnership-oriented programs have succeeded, but what can the cultural heritage preservation community do to move toward the ultimate goal of developing a comprehensive organizational framework? How can we be prepared to meet new challenges that arise?

To move beyond the emergency phase, Afghanistan will need to strike the balance between development, commercial progress, and preservation. In the context of that development, those agendas need to no longer be in conflict with another. What frameworks are required for this type of development?

Perhaps overlaying a framework or system of cooperative engagement on top of existing, often entrenched modes of work is not the most effective measure for engendering effective cooperation. Perhaps a decision-making combination of the central government and foreign groups cannot reach a deeper level of structuring 
that would be truly transformative. Adopting the proactive approach to protecting cultural heritage really means developing university programs to train archeologists, historians, architects, and heritage professionals of the next generation. In fact, it has to go further to the level of the primary school, and to the local mosques and Imams. It is incredibly important that children learn what it means to be part of a nation of Afghanistan with its rich and diverse mix of people; for example, that for a thousand years Afghanistan was a Buddhist country in the period before Islam. If people learn to value those things at a young age, then they are building a foundation in the purest, most proactive way to guarantee a future of protecting heritage.

The emergency phase of cultural heritage preservation will never end; there will always be emergencies and new emergent threats to culture, but what may be happening now is that both the reactive projects and proactive projects are developing in concert. This is a very exciting place to be because at the beginning of this kind of development, that is where there is real room for creativity to propose ideas and to have people who are going to be decisive or willing to take risks to build structures that can really change Afghanistan for the better forever.

Examples of this from other countries include the archeological survey of India that is connected with their own cultural heritage infrastructure. Their job is to document everything possible to act in advance of the economic development that could jeopardize these cultural properties. If the documentation exists at the national level, no one is out there, no one is going to be at risk. Protection exists in advance, and ensures that rescue work is done. So that kind of a proactive structure can be very significant. The key element of this is a proactive structure, which is ultimately based on education and training.

Ideas come from other countries such as some in Africa and Southeast Asia where they have to protect their natural resources against the problem of economic poverty in culturally rich regions. Often in poor villages they set up preserves to protect wildlife. What they found is that if the local population is left out of the equation, animosity develops. But if locals are involved in the general protective structure as managers, developers, and decision makers, then they have a stake in the program. Instead of seeing heritage as their enemy, they see it as their way to a better life. This has positive ramifications down the line, and the goals of many different kinds of organizations are met. And so any framework whose purpose is to optimize the cultural heritage preservation efforts of multiple groups should incorporate at least four levels of engagement: the local government, foreign governments, specialist organizations, and local communities. This is especially true of local communities in the areas that most need protection.

It is an enormous problem to balance the needs of economic development with heritage preservation, but the challenge is more for the government of Afghanistan and for all the international partners to redefine the terms of what that is. It should not cause opposition between the two, because if that is the case then cultural 
heritage will lose every single time. It is important to find ways to ensure that people understand the benefits of preserving heritage. Cultural heritage is a source of pride but a priceless resource, and it is a non-renewable resource.

\section{CONCLUSION}

There is as of yet no definitive answer as to how to institute an overarching framework (or series of frameworks), but from among the points raised above we can see several key ideas emerge that can help. One is simple, critical, but difficult to attain, and that is improved primary, secondary, and undergraduate education in the cultural heritage-related fields (archaeology, history, architecture, museology, etc.). Another is inter-organizational coordination with flexibility. A third is that, whatever the organizing model, the highest level of that body, be it the local government, a cross-cutting committee of various groups, or something else, needs to engage itself in all of the various cultural heritage preservation operations in a reciprocal relationship of coordination and feedback.

The cultural heritage of Afghanistan is too precious to leave it up to chance that preservation efforts and resources will be maximized, at best, and not in opposition to one another or otherwise counter-productive at worst. Perhaps we should think of the development of an organizational framework similarly to the work that it should coordinate. Right now we are in the emergency phase of development of that framework, and we need to do what we can to coordinate the work done the best that we can. But at the same time we should be building cooperative structures from the ground up, so that an effective, long-term framework can emerge organically within the Afghan context. This is the surest way to achieve sustainability of both project and process-to create a system that has iterative sustainability procedures built into it. Many projects and organizations are already doing just that, but we now need to adopt it at the highest coordinating levels and simultaneously bring it into the curricula at the most basic educational levels. This is the way to address the short term cultural heritage problems that Afghanistan faces while ensuring a future where Afghan society itself has an organic means of effecting cultural heritage preservation. 